\title{
AC 2007-2063: TEACHING ELEMENTARY SCHOOL TEACHERS BASIC ENGINEERNG CONCEPTS
}

\section{Marilyn Barger, University of South Florida}

MARILYN BARGER is the Executive Director of FL-ATE, the Florida Regional Center for Manufacturing Education housed at Hillsborough Community College. She earned a B.A. in Chemistry at Agnes Scott College, and both a B.S. in Engineering Science and a Ph.D. in Civil Engineering from the University of South Florida. She has over 16 years of experience in developing curriculum in engineering and engineering technology and is a registered professional engineer in the State of Florida. She is currently working with Douglas L. Jamerson, Jr.

Elementary School to develop curriculum content for its Center for Mathmatics and Engineering.

\section{Richard Gilbert, University of South Florida}

RICHARD GILBERT is a professor of Chemical Engineering in the College of Engineering at the University of South Florida. He has developed educational materials for ISA (Instrument Society of America), AVS (American Vacuum Society) Science Educator's Workshop, and the National Science Foundation through a grant to develop high school science and math curriculum content. He is currently working with Douglas L. Jamerson, Jr. Elementary School to develop curriculum content for its Center for Math and Engineering.

\section{Robin Little, Douglas L. Jamerson Jr. Elementary School}

ROBIN LITTLE is the Engineering Coach at Douglas L. Jamerson, Jr. Elementary School Center for Mathematics and Engineering. She earned a B.A. in Elementary Education and a M.Ed. in Educational Leadership from the University of South Florida. Her experiences include over 23 years in early childhood classrooms and seven years as a teacher resource and trainer. Robin has curriculum writing experience, including a nationally published teacher resource book integrating science and literature with other areas of the curriculum.

\section{Chuck Parsons, Douglas L. Jamerson Jr. Elementary School}

CHARLES PARSONS is the Science Coach at Douglas L. Jamerson, Jr. Elementary School Center for Mathematics and Engineering. He earned a B.A. in Elementary Education from the University of South Florida. His experiences include over 30 years teaching in Kindergarten through fifth grade classrooms and $1 \frac{1}{2}$ years as a resource teacher. Chuck has curriculum writing experience and has presented at various state and national venues.

\section{Kim Parsons, Douglas L. Jamerson, Jr. Elementary School}

KIM PARSONS is the Reading Coach for Kindergarten through Third grade at Douglas L. Jamerson, Jr. Elementary School Center for Mathematics and Engineering. She earned a B.A. in Elementary Education from Florida Atlantic University and a Master of Arts in Education from the University of South Florida. Prior to her position as Reading Coach, Kim's experience included fifteen years as a classroom teacher in grades one through five. Kim has presented at various county and state venues.

\section{Pat Van Driessche, Douglas L. Jamerson, Jr. Elementary School}

PAT VAN DRIESSCHE is a fourth grade teacher at Douglas L. Jamerson, Jr. Elementary School Center for Mathematics and Engineering. She earned a B.S. in Elementary Education from the University of Wisconsin-Superior and her M.S. in Specific Learning and Behavior Problems from the College of St. Thomas, St. Paul, MN. Her teaching experiences include over 30 years teaching first through sixth grade and seven years in exceptional student education. Pat has presented various district trainings and is currently involved in the development of the integrated curriculum at Jamerson. 
Debbie O'Hare, Douglas L. Jamerson Jr. Elementary School

DEBORAH O'HARE is a 4th and 5th grade teacher at Douglas L. Jamerson, Jr. Elementary School Center for Mathematics and Engineering. She earned a B.A. in Elementary Education from Florida State University and has National Board Certification. In 2006, she was one of the finalists for teacher of the year for her district. Her experiences include over 21 years as a classroom teacher in all grades. Her main focus has been in the intermediate grades. Presently, she "loops" with her class from 4th to 5th grade, thus keeping them for two years. Deborah has experience writing curriculum using the Backwards Design Process and has worked with the state to create, revise and edit the math questions used on the statewide test for fifth grade. 


\section{Teaching Elementary School Teachers Basic Engineering Concepts}

There are a variety of ways to increase the engineering knowledge base of elementary school educators. There is no best approach and the selected route for exposure depends on the situation. Some schools will use a few engineering lessons that have been developed by engineering graduate students while other schools will use lessons and "hands-on" activities that are commercially available. However, there are a few elementary schools throughout the country that are developing their entire curriculum using engineering themes. Two examples include, Douglas L. Jamerson, Jr. Elementary School in St. Petersburg, Florida, which has an engineering based curriculum that is in its third year of use, and Martha and Josh Morriss Math and Engineering Elementary School in Texarkana, Texas, which is scheduled to open its doors this fall. In both of these situations, the school districts are supporting and encouraging a strong interaction with an engineering college. This paper will review the characteristics of the professional development plan that is in place at Douglas L. Jamerson, Jr. Elementary School.

\section{Background}

The school was built in 2003 in a predominantly ethnically isolated inner city neighborhood. Its location facilitated ethnicity integration without the aid of a district assigned plan. During its first year of operation, the school applied for and received a three year grant from the Magnet Schools Assistance Program (MSAP) that provided additional resources to support its curriculum and faculty development. The school has a K-5 student population with no special enrollment criteria and definitely functions as a typical neighborhood school. It has more than 600 students and at least 3 classrooms at each grade level. Student talents and abilities are normally distributed and there is no grouping of mainstream students by sections, test scores, and/or perceived ability. Every teacher at each grade level is expected to present the same curriculum. The topics and order of these presentations is driven by lesson plans that are horizontally and vertically integrated. A unique aspect of the curriculum and therefore a demand on its professional development plan is the fact that the school does not have a specific engineering instructional period. Teachers integrate the engineering content throughout the subject areas standards-driven component of its educational mission. This approach forces each teacher to find ways to use these subjects to strengthen the understanding of the engineering topics being taught which then, in turn, enrich the student's core "reading, writing and arithmetic" learning experiences.

From a faculty development perspective, the decision by the Jamerson faculty and administration to dissolve engineering into all aspects of the school's learning culture created some interesting opportunities and challenges. The tight weave of engineering into daily lessons meant that our teachers must not just acquire a bit of knowledge about the distinctions among chemical, civil, electrical, industrial, and mechanical engineering. Ironically, these distinctions are of minimal educational value since all but the superficial characteristics are lost on the students, but of some political worth since the general public thinks they do understand such distinctions. More to the point, our teachers have to learn enough engineering science so that they start to see how engineering has a significant impact on peoples lives, how it is driven by a strong knowledge of 
mathematics and science, and how this knowledge base can easily strengthen all of the "traditional" lessons typically used by teachers in other elementary schools in our district.

\section{Introduction}

With this background in mind, how do you get elementary school teachers to teach their students engineering concepts integrated throughout their curriculum in a developmentally appropriate way? The success of Douglas L. Jamerson, Jr. Elementary School Center for Mathematics and Engineering Program, Pinellas County, FL, is largely built upon the track we took in answering this question. Over three years ago as we began to build an engineering program for our brand new school, we knew that teacher professional development would be the key to our success. At that time, there were a few model options. Although a "turn-key" curriculum was not available, there were some commercial products that did provide an engineering element for elementary education. Such packages have the attractive component that "training" would be provided by the vender and the classroom materials were provided. We examined this approach and concluded that the product versatility was limited and the training provided would not generate the depth and breadth we needed for the content integration we desired.

We also elected not to base our professional development on the NSF G-K12 program resources. Although the excellent examples from this program as presented at ASEE conferences do provide curriculum content and professional development related to that specific engineering context, they do not meet our universal needs nor do they strengthen the faculty as an integrated teaching unit. Ultimately, we decided that our overall expectations for our curriculum place an overall demand on our faculty. This requires a continuous improvement approach that would give a substantial number of teachers, our core collection of teachers across all grade levels, the confidence to implement our lessons and guide new teachers as well.

As an initial step in the creation of our professional development plan, we determined the resources that would or could be available. Fortunately, the Tampa Bay region of Florida has two engineering and technical educational resources, the College of Engineering at the University of South Florida, and Florida's NSF supported Regional Center for Advanced Technological Education (FL-ATE) that could and did provide important guidance and assistance. In addition, the Pinellas County School District provided the resources and flexibility for us to develop Professional Learning Communities at each grade level. The MSAP grant supported intensive short courses for our teachers at the beginning and end of the school year. Finally, the school district helped us optimize our learning time and energy by allowing us to focus all of our professional development activities on our needs while simultaneously meeting most of the general professional development requirements imposed on teachers in the district.

\section{Douglas L. Jamerson, Jr. Elementary School's Professional Development Plan}

The Douglas L. Jamerson, Jr. Elementary School blend of these resources has lead to a professional development plan for our teachers that has three operational levels; the formal educational level, the "just-in time" educational level and the professional learning community level. In our formal educational level, we have partnered with the College of Engineering to develop a series of three graduate level courses designed for our teachers. Although enrollment 
is open to any in-service teacher, the nature, intensity and focus of the material has limited enrollment to teachers at our school. These courses have engineering science and design components with considerable emphasis on the science and mathematics associated with the conservation laws. (This knowledge and skill set components does not easily blend into other schools in the district.)

An important characteristic of these courses is their presentation style and expectations of participants. The material presented is not "watered" down by any means, but it is adjusted to the target audience and extensive "homework" assignments are not practical for these working elementary school teachers who typically have school related responsibilities well after the school day is done and also have a dual responsibility with respect to writing their own integrated engineering units. In addition there are no fixed final performance expectations and the course material delivery pace is governed by the teachers.

This approach may seem to be loaded with radical elements. At first glance, it may seem that the course's no "homework" practice does not fit the normal practice these same teachers use in their own classroom. It also seems to run counter to a number of givens in their lives especially since teacher career advancement seems to dictate that they pursue one or more masters degrees with the corresponding homework. Finally, the idea of conducting a course with no fixed final performance expectations might be just a bit "around the bend". Naturally, these are all genuine concerns and this course set does not blatantly ignore the good practices expected of any course. However, it is one thing for an in-service teacher to succeed when writing papers and/or doing literature research in a method course or principles of school administration course and quite another for a teacher with no or at best absolute minimal previous exposure to engineering science and design to survive an engineering education experience that uses the usual course structure tools such as extensive homework, quizzes, and/or test assessments to demonstrate their learning success. From a practical perspective, the teachers will not do such homework nor will they find the time to practice (study) for the quiz. They just don't bring that experience into the classroom because they do not have the math and science background to perform at that level.

Despite the message of the previous paragraph the course has tangible deliverables. Course participants are writing their own integrated engineering units. This makes the content that they intend to use in their classrooms the course deliverable. Thus the teachers are expected to work out how the class content is incorporated into this engineering curriculum. As the content is presented in class, discussion occurs as to how the engineering concepts can be worked into the vertical alignment of the curriculum. Final outcomes of their learning experience will be evident in the written lessons that are created and presented during the course.

These courses do have two overriding constraints. First, engineering in our elementary school is by the nature of the elementary school students going to be rudimentary, but it can still possess the essence of an engineering experience. Second, the objective of the professional development is not to turn the teachers into engineering students but to transition the engineering into ideas, concepts, lessons, and activities that children at various elementary grade levels can use. Each of the engineering courses requires as much skill from our teachers to help with that translation as it does with our learning the core concept in the first place. This second constraint is what requires that the course pace be dictated by us and not the professor. Thus, forces and force fields as they 
apply to the cars (live loads) moving over student designed bridges and/or charges moving on a wire or magnets generating a current are course topics but so are the ways the science and math to support these topics can and will be taught in the classroom in a grade level appropriate manner. In this way, the courses represent a formal way to increase teacher knowledge base, a mechanism to develop teaching opportunities in our elementary school classrooms, and a stateof-the-art evolving instructional tool that could be used with teachers in training.

Our three 3 credit courses proceed through the following topic areas; gravitational and electrostatic force and force fields with engineering applications, material science fundamentals including band gap theory and properties of materials, energy balance and phase change fundamentals, transport processes, and life science topics as reflected in biomedical engineering examples. In many case, the information presented in a class is new to us. In all cases, the course materials emphasis that engineering "hands-on" learning experiences and/or design challenges we develop should be governed by actual values associated with an appropriate engineering parameter as expressed as a scalar or a vector. This is important because it represents a specific way that engineering does make our curriculum unique to elementary education and exciting to our students. Course resources include the following

- $1^{\text {st }}$ chapter of "Fundamentals of Applied Electromagnetics" by Fawwaz T. Ulaby.

- The series of articles in American Scientist by Henry Petroski.

- Various engineering college faculty course web sites.

- Selected math/science examples from district adopted middle and high school texts.

- General Google searches on topics as they arise in class.

- "Hands-on" activities for conversion to the classroom environment.

In addition to the formal educational level described, there is also a "just-in-time" educational level. This training comes in two forms and is delivered as before and after the school year workshops. The pre-school year workshops are grant sponsored events and the topics covered are determined in coordination with the curriculum writing activities that are targeted for that school year. Because the school is horizontally integrating its engineering theme across all topics taught at grade level as well as vertically integrating the school's math and science programs with engineering, we are using MSAP grant funds to support our effort to write our entire curriculum. The "pre-school" workshop is used to coordinate that writing by reviewing the math, science and social impact an engineering topic can provide to the lessons to be developed and tested that year. The "post-school" year workshop has a different mission. This workshop is used to provide detailed engineering science instruction as it relates to an engineering topic. Teachers that attend this workshop are members of our leadership team. The goal is to expand our horizons and increase our skills to accomplish specific tasks. For example, one workshop dealt with scalar and vector mathematics as it relates to force and free body diagrams. This topic was completely outside our experience and required a comfort level with mathematics that we did not have. Without specific help in this area, we could not have developed our fourth and fifth grade lessons that use such diagrams nor have force based or test to failure type challenges that actually do reflect how engineers think

The third level of our professional development plan is the formation of the Professional Learning Community (PLC). The structure of PLC's at Jamerson Elementary provides a specific time for teachers at the same grade level to work on new or refined lessons and teaching 
ideas every week. It will also be the main vehicle for sustaining our plan after the MSAP grant is completed. In its current form, our engineering professor advisors have multiple opportunities to work directly with our teachers. They rotate each week to different grade level teams to guide curriculum development as each grade level vertically integrates their units. Sometimes this takes the form of a question and answer session while other times it might be working through an engineering design challenge as a team to help understand or redesign it. In addition, they may join a grade level team on one of their eight curriculum writing days per year. Finally, they are available by phone or email and make every effort to provide answers to questions that help move the curriculum development along at a steady pace.

As an extension to the PLC, our engineering professor advisors also work closely and routinely with the MSAP supported curriculum coaches. Douglas L. Jamerson, Jr. Elementary School has three full-time coaches, an Engineering Coach, a Science Coach, and a Mathematics Coach, to help develop math and engineering concepts at a leadership level. These coaches are working daily with the teachers, modeling or co-teaching math and engineering lessons directly with the students. By providing the coaching needed, many of the classroom teachers are then empowered to try the next lesson on their own. The guidance provided to the coaches is readily available and freely given. This PLC extension feature has been instrumental in the development of the engineering integrated curriculum units at Jamerson. 